\title{
MANUFACTURING OF LARGE IN 706 AND IN 718 FORGING PARTS
}

\author{
P. PETIT - J.P FESLAND
}

Aubert \& Duval, Les Ancizes, France

\begin{abstract}
$\underline{\text { Abstract }}$
Whatever the industrial field, the performances improvement and the new technologies require the use of larger ingots in order to produce large diameter billets and larger parts manufactured with alloys offering better combination of properties such as supcralloys.

For land gas based application, AUBERT \& DUVAL currently and successfully manufactures large alloy 706 rotating components issuing from ingots as large as $1020 \mathrm{~mm}$ in diameter and 20 metric tons in weight. This great experience, acquired owing to a well-controlled process, is briefly reviewed.

Now, the constant need to achieve higher temperature and consequently better efficiency in new advanced gas turbine requires material with higher properties at elevated temperature. Fine grain alloy 718 is the alternative.

To meet this challenge, a process development work has been undertaken to produce a trial disc with a $2000 \mathrm{~mm}$ diameter and a $300 \mathrm{~mm}$ thickness using a triple melted $710 \mathrm{~mm}$ diameter ingot. The paper reviews this development program and presents promising results.
\end{abstract}




\section{INTRODUCTION}

Advanced gas turbine need high power output with high efficiency leading to increased firing temperature. The rotating components are highly stressed at higher temperature range. The material becomes the critical parameter.

In the Mid 80's, alloy 706 was selected for this application in place of low alloy steels because of its interesting mechanical properties and especially its low hardening elements contents. (1) Alloy 706, which is derivated from alloy 718, has a reduced niobium content in order to decrease the tendency for segregation and freckle formation and consequently to allow to produce the necessary large diameter ingots.

For this application, AUBERT \& DUVAL has developped well-controlled melting and forging process owing to powerful and well-adapted facilities, and especially detailed research works at each step of the manufacturing process. (2) Up to now, more than 300 parts - with diameters up to $2300 \mathrm{~mm}$, thicknesses up to $400 \mathrm{~mm}$ and weights up to 12 tons - have been successfully manufactured. An up-dated status is presented.

The larger and more agressive gas turbine designs leading to highest efficiency require an alloy offering better properties at highest temperature and also a better stability during a long term exposure at the in-service conditions. Alloy 718 is the alternative. Due to its high hardener content, alloy 718 has a strong tendency for macrosegregation and microsegregation. Thus, the demand for large ingots with diameter higher than $610 \mathrm{~mm}$ and for components as large as those produced in alloy 706 but with a very fine grain structure is a big challenge. This paper describes also recent works to develop a $710 \mathrm{~mm}$ diameter ingot by the triple melt route and next to manufacture a large part with a $2000 \mathrm{~mm}$ diameter and a $300 \mathrm{~mm}$ thickness.

The two alloys, subjects of this presentation, are given in table I.

Table I : Nominal alloy composition in weight percent

\begin{tabular}{|c|c|c|c|c|c|c|c|c|}
\hline & $\mathbf{C}$ & $\mathbf{C r}$ & $\mathbf{M o}$ & $\mathbf{A l}$ & $\mathbf{T i}$ & $\mathbf{F e}$ & $\mathbf{N b}$ & $\mathbf{N i}$ \\
\hline Alloy 706 & $<0.02$ & 16 & - & 0.15 & 1.7 & 38 & 3 & base \\
Alloy 718 & $<0.03$ & 18 & 3 & 0.5 & 1 & 18 & 5 & base \\
\hline
\end{tabular}

\section{ALLOY 706 FORGING}

In the 1990 's, the use of alloy 706 for heavy duty industrial gas turbine forgings bccame widespread. The size of these forgings can reach weights up to 12 tons with diameters up to $2300 \mathrm{~mm}$ and thicknesses up to $400 \mathrm{~mm}$.

AUBERT \& DUVAL is very widely involved in the manufacturing of such forgings. Up to now, more than 300 parts have been successfully produced.

As a melter and forger, AUBERT \& DUVAL has succeeded to develop a robust whole manufacturing process allowing to produce :

- ingots as large as $950 \mathrm{~mm}$ and $1020 \mathrm{~mm}$ in diameter without detrimental

segregation by the triple melted route (VIM + ESR + VAR)

- large and complex forgings meeting the required properties 
Since the previous paper on this subject, persistent efforts in R\&D and in production have been made to improve the process and its consistency.

A narrow control of significant parameters such as remelting rate, forging reduction ratio, solutionning temperature .... has allowed to reduce manufacturing cycle times : indeed, mults can be immediately forged after ends cropping without waiting macroetching results, and especially parts can be shipped without waiting mechanical tests results in case of urgent delivery.

The forging shape is become different due to the extended alloy 706 use. Large aft shafts, consisting of a cone region with a maximum diameter up to $1600 \mathrm{~mm}$ and a tail with a diameter up to $660 \mathrm{~mm}$, have been produced. These parts can attain lengths up to $1500 \mathrm{~mm}$ and weights up to $4.5 \mathrm{~T}$. The manufacturing process had to be optimised in order to satisfy the required properties especially grain size homogeneity and ultrasonic inspectability. The ingot to billet conversion practice is remained unchanged, consisting in multiple upset and draw operations to break up the initial large as-cast grain structure. Contrary to disk forgings, the billet needed to be preformed on the 4500 tons press before the final close die forging on the 65000 tons press. The forge modelling tools have been very helpful in order to define the preform shape and the appropriate thermomechanical parameters (temperature reduction ratio).

Our better understanding of dynamic and static recrystallization mechanisms on alloy 706 acquired by numerous torsion testing performed in AUBERT \& DUVAL, has prompted us to adjust some forging parameters. This modification has lead to a better homogeneous grain structure and consequently to a significant improvement of ultrasonic inspectability as shown in figure 1 .

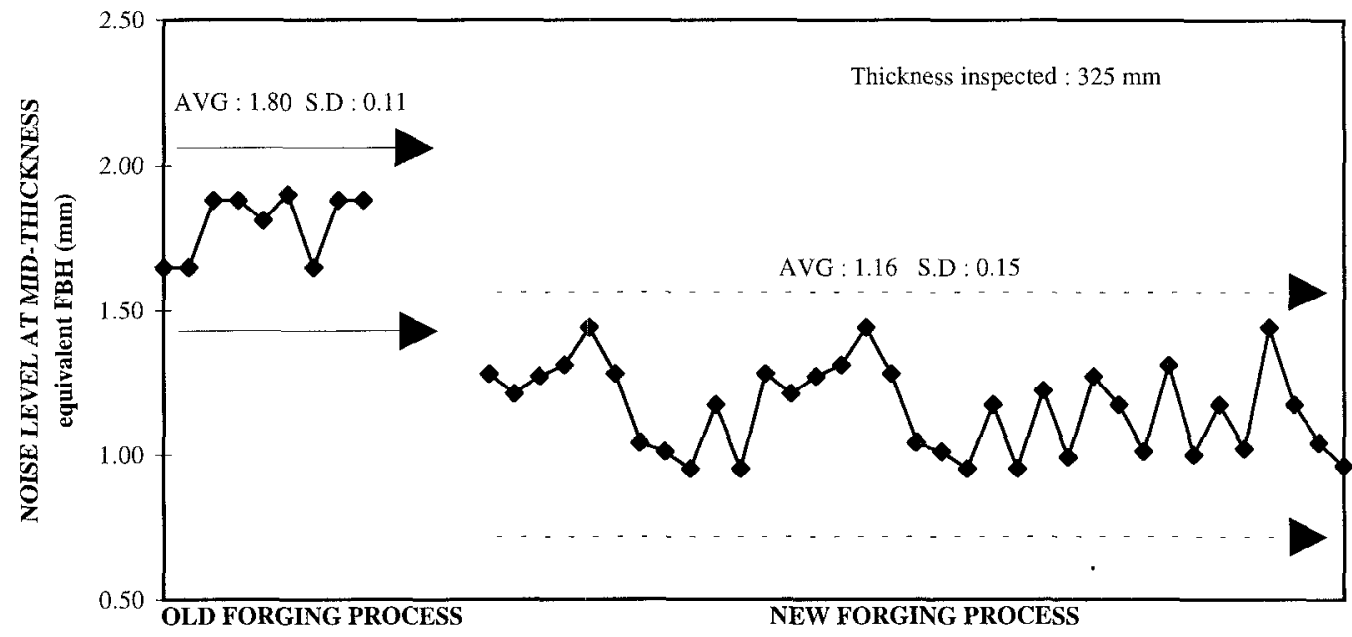

Figure 1 : Noise level improvement by forging process optimization

The present typical structure in solutionned and aged condition is fully recrystallized with grain size of ASTM 3/4.

By conventional ultrasonic examination methods using a $2.25 \mathrm{MHz}$ long wave beam, this structure allows to detect defects equivalent to flat bottom holes varying from $1.2 \mathrm{~mm}$ to 2.2 $\mathrm{mm}$ according to thickness to check. 
The associated average mechanical properties including tensile, CVN and fatigue data are presented in table II.

Table II : Mechanical properties heavy section alloy 706 forging

\begin{tabular}{|c|c|c|c|c|c|c|c|c|c|c|}
\hline \multirow{3}{*}{ Location } & \multirow{3}{*}{ Dir. } & \multicolumn{4}{|c|}{$\begin{array}{l}\text { ROOM TEMPERATURE } \\
\text { TENSILE }\end{array}$} & \multirow{3}{*}{$\begin{array}{c}\text { CVN } \\
\mathrm{J}(\mathrm{Ft}-\mathrm{Lbs})\end{array}$} & \multicolumn{4}{|c|}{$\overline{\mathrm{LCF}}$} \\
\hline & & \multirow{2}{*}{$\begin{array}{l}\text { UTS } \\
\text { Mpa } \\
\text { (ksi) }\end{array}$} & \multirow{2}{*}{$\begin{array}{c}0,2 \% \mathrm{Ys} \\
\mathrm{MPa} \\
(\mathrm{ksi})\end{array}$} & \multirow{2}{*}{$\begin{array}{c}\mathrm{El} 4 \mathrm{~d} \\
\%\end{array}$} & \multirow{2}{*}{$\begin{array}{c}\text { RA } \\
\%\end{array}$} & & \multicolumn{2}{|c|}{$400^{\circ} \mathrm{C}\left(750^{\circ} \mathrm{F}\right)$} & \multicolumn{2}{|c|}{$480^{\circ} \mathrm{C}\left(900^{\circ} \mathrm{F}\right)$} \\
\hline & & & & & & & $\varepsilon=0.6 \%$ & $\varepsilon=0.7 \%$ & $\varepsilon=0.6 \%$ & $\varepsilon=0.7 \%$ \\
\hline \multirow{2}{*}{ RIM } & & $\begin{array}{l}1264 \\
(183)\end{array}$ & $\begin{array}{l}1022 \\
(148)\end{array}$ & 21.8 & 40 & $\begin{array}{c}76 \\
(56)\end{array}$ & & & 19130 & 11240 \\
\hline & Axial & $\begin{array}{l}1200 \\
(174)\end{array}$ & $\begin{array}{l}1018 \\
(147)\end{array}$ & 19.4 & 33 & $\begin{array}{c}41 \\
(30)\end{array}$ & & & & \\
\hline \multirow{2}{*}{$\begin{array}{l}\text { CORE } \\
\text { BAR }\end{array}$} & & $\begin{array}{l}1230 \\
(178)\end{array}$ & $\begin{array}{l}1025 \\
(148)\end{array}$ & 20.9 & 37 & $\begin{array}{c}68 \\
(50)\end{array}$ & 23910 & 6810 & & \\
\hline & Axial & $\begin{array}{l}1189 \\
(172)\end{array}$ & $\begin{array}{l}1018 \\
(147)\end{array}$ & 15 & 27 & $\begin{array}{c}37 \\
(27)\end{array}$ & & & & \\
\hline
\end{tabular}

\section{ALLOY 718 FORGINGS DEVELOPMENT}

\section{Melting process}

Alloy 718 is the most frequently used alloy for aircraft industry applications. For such an alloy, the need to control carbon content, tramp elements and to prevent reactive alloying elements from oxidizing, requires the use of vacuum induction melting (VIM). Different remelting practices can be considered : Vacuum Arc Remelting (VAR), Electroslag Remelting (ESR) or both (ESR + VAR). Due to its high niobium content (5.4\%), Alloy 718 is prone to segregation and particularly to form freckles. Thus, for critical applications such as rotating parts, the ingots, limited to $500 \mathrm{~mm}$ diameters, are only produced by the two following routes : VIM + VAR or VIM + ESR + VAR.

Recently, a new demand for improving land based gas turbine efficiency is arisen : manufacturing industrial gas turbine alloy 718 forgings as large as those made in alloy 706 . First of all, this technical challenge has required the development of large, high quality alloy 718 ingots with diameters higher than $500 \mathrm{~mm}$.

To hope producing segregation free large ingots, alloy 718 chemistry has been reviewed :

- niobium content reduction to $5 \%$ level to prevent freckles formation

- carbon content reduction to minimize stringering and increase chemical homogeneity during solidification.

AUBERT \& DUVAL has undertaken, a program to develop a $710 \mathrm{~mm}$ diameter ingot with this modified chemistry.

The triple melting route (VIM + ESR + VAR), which is considered more prudent and more viable for such large ingots, is essential. 
The intermediate electroslag remelting is introduced to remove large inclusion agglomeration and to produce a fully dense electrode with no skrinkage cavities, allowing thus a more stable VAR process with less potential for melting anomalies. However, the poor ESR heat transfert profile, resulting from the slag cover and slag skin, produces deeper molten pools, leading to a higher degree of segregation related defects.

A final VAR process is thus necessary to get a better control of solidification (shallower molten pools). AUBERT \& DUVAL's VAR process control is fully automated with proprietary software integrating load cells sensors.

For each ingot size and each alloy, it's necessary to optimize the melt parameters.

In alloy 718 low niobium, several $710 \mathrm{~mm}$ diameter trials ingots approaching 7 tons have been cut-up in as-cast and as-forged condition in order to evaluate significant melt parameters (such as start-up and hot topping procedures, drip-short, melt rate) and to determine the aim level for such parameters and especially melt rate, the major one.

Indeed, a too high melt rate results in generalized positive segregation such as freckles as shown in Figure 2. On the contrary, when the melt rate is too low, excessive solidification white spots can occur. Typical solidification white spots in an large alloy 718 billet slice from a melting experiment are shown in figure 3. They have a hook-like or full-circle appearance. They have been observed near the surface, even on the whole height of the ingot, but are more prevalent at the bottom end.
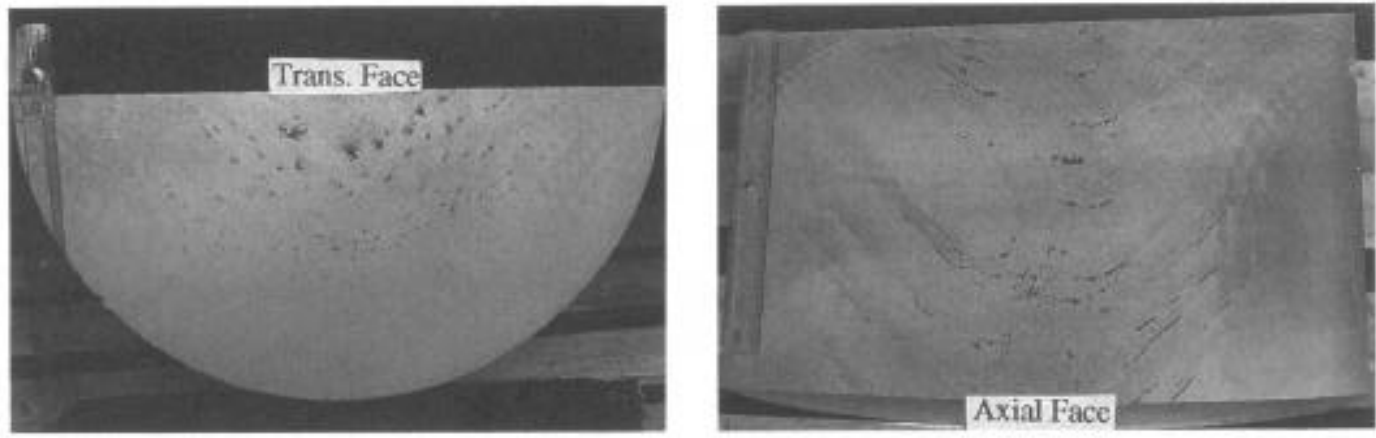

Figure 2: Large freckles on transverse and longitudinal alloy 718 billet slices from a $710 \mathrm{~mm}$ diameter experimental ingot melted at a too high melt rate

Due to its small chemical depletion and thermomechanical process history, this defect can exhibit no significant coarser grain structure, as shown in figure 4, making it difficult to detect. (3) 


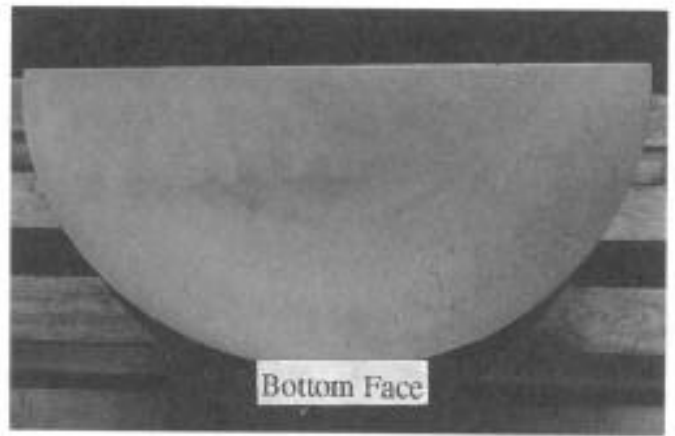

Figure 3 : Numerous solidification white spots in an alloy 718 bottom billet slice from a $710 \mathrm{~mm}$ diameter experimental ingot melted at a too low melt rate

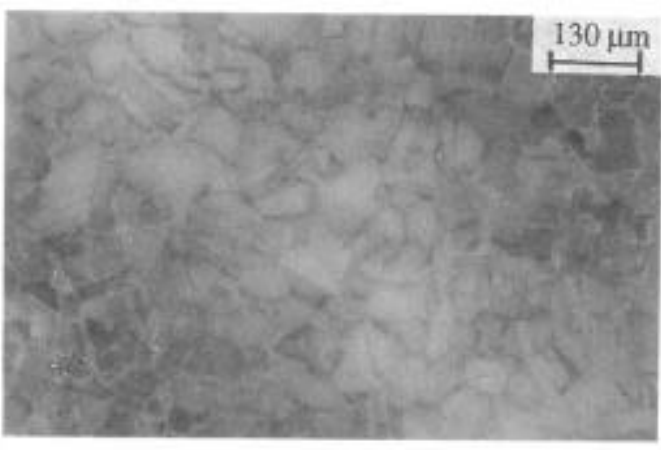

Figure 4: Solidification white spot in an alloy 718 billet slice showin no grain growth

The melting experiments have lead to the following attainments :

- molten pool profile and depth have been evaluated as a function of melt rate

- to reach the objective, the VAR melt rate process window is narrow.

- its appears possible to develop a melting process allowing to produce a $710 \mathrm{~mm}$ diameter ingot weighing more than 10 tons with a satisfactory metallurgical quality : no freckle, and only few solidification white spots observed at bottom end, in area which is widely included in normal ends cropping performed at billet stage.

\section{Thermomechanical process}

Ingots conversion

Superalloys have been found to be difficult to fabricate, particularly into large forged parts. Therefore, it's difficult, as well as undesirable, to attempt to correct deficiencies in the billet at the final forging stage.

To meet the challenge for large alloy 718 forgings, the ingot to billet conversion had to be developed in order to produce good quality billets characterized by :

- a homogeneous macro/microstructure with grain as fine as possible to help ultrasonic inspectability

- the end to end chemical variations being controlled by the melting practice.

These objectives have required the fine tuning of several parameters :

- a homogenizing practice, necessary to reduce interdendritic segregation and to dissolve brittle phases, has been fixed thanks to, firstly, our great experience acquired on standard alloy 718 products and on large alloy 706 ingots, and secondly, our laboratory works carried out to understand solidification path by DTA, SEM, EDS methods and to evaluate different thermal cycles by microphobe analysis 
- the conversion of such ingots consists in multiple upsetting and drawing operation to break in all areas the coarse as-cast grains structure.

The large size of these ingots (high diameter, high height/diameter ratio) has required specific pot dies to allow the ingot upset and also a appropriate pair of forging temperature/strain parameters ; this thermomechanical parameters choice taking in account the metallurgical requirements deduced from torsion testing and the available forging capacities.

The $710 \mathrm{~mm}$ diameter trial ingots evaluating the significant melt parameters have been also used to test different conversion process. These trials have allowed us to develop a forging process able to achieve, on a $790 \mathrm{~mm}$ diameter billet, a homogeneous structure with grain size equivalent to ASTM 4. Due to the billet size, this rather fine structure doesn't allow a sufficient ultrasonic inspectability.

\section{Parts forging process}

The size of the parts to manufacture in alloy 718 is impressive : diameters up to $2000 \mathrm{~mm}$, thicknesses up to $325 \mathrm{~mm}$. The structure of such parts must be widely recrystallized with grains as fine as possible, preferably finer than ASTM 8 for both mechanical properties and sonic inspectability reasons.

In as much as the billet grain structure in not enough fine to get this aim, the forge route must be designed to refine this structure by achieving, on the component, an averall high degree of strain. In order to optimize this forging process with respect to microstructure,

AUBERT \& DUVAL has used all these available forging and modelling means such as FORGE 2, THER 2, torsion testing machine ....

On material representative of billets structures, a large torsion testing programm has been undertaken, obviously to determine the requisite rheological databases for forge modelling and especially to better understand the dynamic and static recrystallization mechanisms governing this specific alloy and to developp qualitative and quantitative prediction of microstructure during hot working.

Several thermomechanical parameters have been thus evaluated : forging temperature, strain, initial grain size ....

It emerges from this work the following main points :

- a complete dynamic recrystallization requires an high strain level, which is rarely achieved on parts. As shown in figure 5, whatever the temperature and initial grain size tested, the recrystallized fraction exhibits a sharp increase at a specific strain level.

- for lower strains, a fully recrystallized state can be achieved after deformation by metadynamic recrystallization (static mechanism) occuring during holding time of one hour minimum at the same tested temperature. The recrystallized grain size evolution as a function of strain, initial grain size and temperature is shown in figure 6.

A grain size limit of $20 \mu \mathrm{m}$ (ASTM 8/9) seems to be reached in as forged + annealed condition.

- the particles of delta phase which are know to pin the grain boundaries and to prevent grain growth, would increase the dynamic recrystallization kinetics 


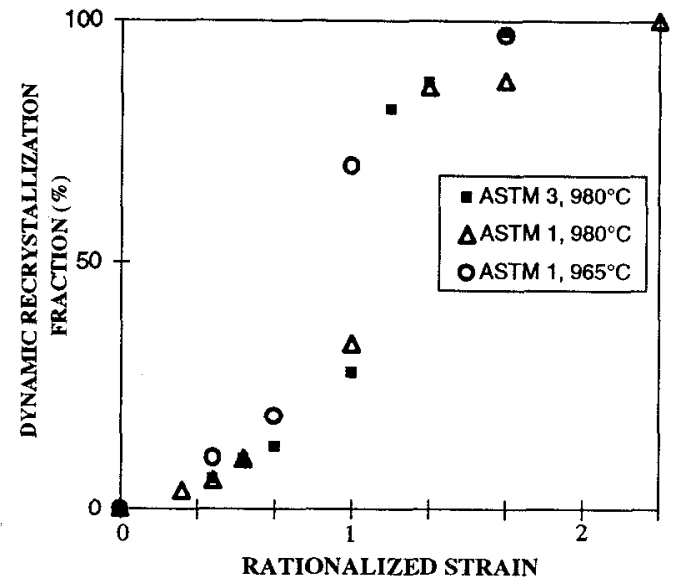

Figure 5 : dynamic recrystallization fraction as function of strain temperature and initial grain size

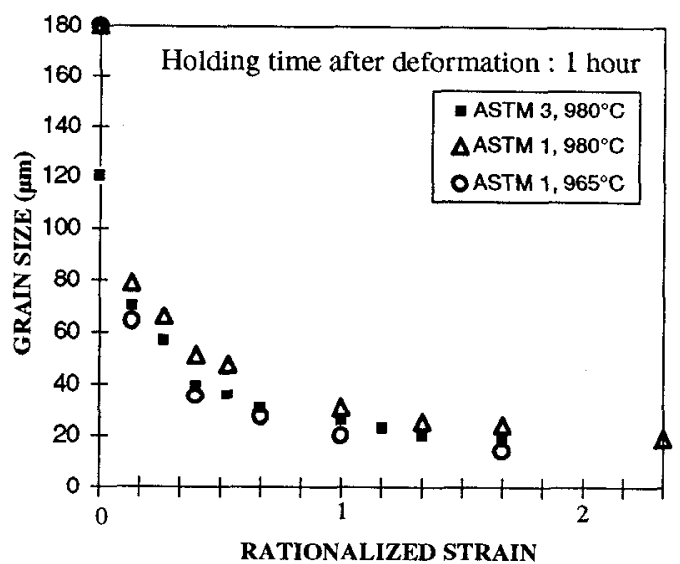

Figure 6 : recrystallizated grain size as a function of strain, temperature and initial grain size

To validate these laboratory results, an experimental subscale pancake-diameter of 1700 $\mathrm{mm}$, thickness of $210 \mathrm{~mm}$ - has been forged and cut-up in both as-forged and as-heat treated conditions. The metallurgical results were in good agreement with the laboratory attainments.

We have only noted that :

- the $\delta$ phase precipitation is more marked on the pancake

- the static recrystallization mechanisms seem slowler on the pancake in as much as some unrecrystallized grains remain and the recrystallised grains size is slightly finer (ASTM 9/10).

These differences can be explained by the internal stress distribution induced on large parts.

On the basis of the above preliminary studies, a forging process has been developped to produce a large trial disk, usually made in alloy 706 - diameter of $2000 \mathrm{~mm}$, thickness of 300 $\mathrm{mm}$. The manufacture of this part has used a $790 \mathrm{~mm}$ diameter billet with average grain size of ASTM 4 issuing from a $710 \mathrm{~mm}$ diameter ingot weighing more than 10 tons.

Due to the size of the part, the die forging operations have been performed on the 65000 tons press (partly owned by AUBERT \& DUVAL) which allows the optimizing of the temperature/reduction ratio pair of parameters.

\section{Characteristics of large alloy 718 trial forging}

After heat treatment (solutionning + aging) and machining, this part has undergone non-destructive testing.

The disk has been ultrasonically inspected using a $2.25 \mathrm{MHz}$ probe and no indication has been found. Grass level is equivalent to flat bottom hole $0.5 \mathrm{~mm}$ at mid-thickness and 0.7 $\mathrm{mm}$ near backwall echo.

The macroetch inspection, performed on the disk surface, has revealed no large grains, no segregation such as freckles, white spots or solidification white spots. 
The cut-up of this part is in progress. Nevertheless, some interesting metallurgical results have been obtained on core bar and test ring.

The typical grain structure consists of fine recrystallized grains varying from ASTM 8 to 10 duc to the interdendritic segregation with the occurence of some unrecrystallized grains, ASTM 4-6 in size, in the low strain areas.

The associated average mechanical properties are presented in table III.

Table III : Mechanical properties

\begin{tabular}{|c|c|c|c|c|c|c|}
\hline \multirow{2}{*}{$\begin{array}{c}\text { Tested } \\
\text { Temperature } \\
\left({ }^{\circ} \mathrm{C}\right)\end{array}$} & Dir. & \begin{tabular}{c} 
UTS \\
\cline { 3 - 6 } \\
\cline { 3 - 6 }
\end{tabular} & $\begin{array}{c}\text { MPA } \% \text { YS } \\
\text { MPA } \\
(\mathrm{ksi})\end{array}$ & $\begin{array}{c}\text { El 4d } \\
\%\end{array}$ & $\begin{array}{c}\text { RA } \\
\%\end{array}$ & $\begin{array}{c}\text { CVN } \\
\text { J (Ft-Lbs) }\end{array}$ \\
\hline 20 & Tang. & $1432(208)$ & $1123(163)$ & 18.2 & 31.2 & $24.5(18)$ \\
400 & Axial & $1398(203)$ & $1101(160)$ & 16 & 22 & $15(11)$ \\
\hline 538 & Tang. & $1249(181)$ & $999(145)$ & 23.2 & 42 & \\
\hline
\end{tabular}

\section{CONCLUSIONS}

Owing to powerful and well-adapted melting and forging facilities, and detailed research works at each step of the manufacturing process, AUBERT \& DUVAL has succeeded the development of large alloy 706 forging parts. The industrial experience covers now more than 300 parts meeting all of the requirements specified in terms of macro/microstructure and mechanical properties. Persistent efforts are made both in Research and Development and in production to continuously improve the process and its consistency.

The same development programm has been recently undertaken on alloy 718 with a slightly modified chemistry (lower carbon and niobium content).

A manufacturing process seems to be achievable to produce :

- a $710 \mathrm{~mm}$ diameter ingot free from freckles by the triple melt route VIM + ESR + VAR

- a large forging disc - diameter of $2000 \mathrm{~mm}$ and thickness of $300 \mathrm{~mm}$ - with a grain structure finer than ASTM 4.

These promising results represent a significant scaling-up in size from previous alloy 718 manufacturing experience. Nevertheless, they need to be confirmed by the complete cut-up of the trial disc and on several production ingots and forgings.

The fact of controlling the whole manufacturing process (ingot melting and conversion, parts forging, heat treatment ....) is a significant advantage which allows :

- a good understanding of all the phenomena (metallurgical and others) and theirs interactions

- a easier reduction of manufacturing cycle times. 


\section{References}

1 - P.W Schilke, J.J Pepe, R.C Schwant "Alloy 706 metallurgy and turbine wheel application", Superalloys 718.625.706 and various derivatives, ed E.A Loria, The Minerals, Metals \& Materials Society, 1994, 1-12

2 - J.P Fesland, P. Petit "Manufacturing alloy 706 forgings", Superalloys 718, 625, 706 and various derivatives, ed. E.A Loria, The Minerals, Metals \& Materials Society, 1994, 229-238

3 - L.A Jackman, G.E Maurer, S. Widge, "White Spots in Superalloys", Superalloys 718, 625, 706 and various Derivatives, ed E.A Loria, The Minerals, Metals \& Materials Society, 1994, 153-166 